\title{
Special issue on the Impact of endocrine disrupters on reproductive health
}

\author{
Anna-Maria Andersson, Hanne Frederiksen, Kenneth M Grigor ${ }^{1}$, Jorma Toppari ${ }^{2}$ and \\ Niels E Skakkebæk \\ Department of Growth and Reproduction, Rigshospitalet, Blegdamsvej 9, Copenhagen 2100, Denmark, \\ ${ }^{1}$ Department of Pathology, Western General Hospital, Edinburgh, UK and ${ }^{2}$ University of Turku, Turku, Finland \\ Correspondence should be addressed to A-M Andersson; Email: Anna-Maria.Andersson@regionh.dk
}

Reproduction (2014) 147 E1

This special issue of Reproduction contains articles based on presentations at the 7th Copenhagen Workshop on Endocrine Disrupters, which took place in May 2013. The workshop was the seventh in the series of successful meetings held at Rigshospitalet in Copenhagen since 2000 with the aim of bringing together leading scientists across disciplines to discuss the latest aspects of endocrine disruption with focus on human health, particularly on reproduction. More than 200 scientists from all over the world and from a wide variety of disciplines including endocrinology, basic science, toxicology, reproductive biology, immunology, chemistry, environmental health, and epidemiology gathered for 4 days during the meeting.

The papers in this special issue reflect the diversity in the fields of science that contribute to our knowledge on how environmental factors can affect hormone systems and thereby compromise health. Reports on the associations between human exposures and different health outcomes from epidemiological and clinical research are accompanied by reports from studies on experimental animal and laboratory models. One of the sessions at the workshop was dedicated to species differences in endocrine-disrupting effects, including a report of comparative studies that calls for caution in the extrapolation of effects between species (Habert et al. 2014).

Comprehensive new data on human exposures to a range of mainly non-persistent chemicals present in our daily environment are also presented (Frederiksen et al. 2014) including a study showing that aniline, to which whole populations are exposed, is a hitherto overlooked source of exposure to paracetamol - a pharmaceutical compound - recently shown to affect the production of testosterone (see Modick et al. (2014) in this issue).

For the articles that closely reflect the original presentation at the meeting, the edited comments from the audience during the workshop are included at the end of the paper. This was done to provide an impression of the scientific discussions that took place as well as to retain the added information that such discussions might provide. All papers accepted for this volume have passed the thorough peer review process of Reproduction.

The workshop was financially supported by the Danish Ministry of Environment as an activity under the Danish Center for Endocrine Disrupters (www.cend.dk). We also gratefully acknowledge the Society for Reproduction and Fertility for the generous support for publication of the workshop proceedings as this special issue of Reproduction.

\section{References}

Frederiksen $H$, Jensen TK, Jørgensen $N$, Boye Kyhl $H$, Husby $S$, Skakkebaek NE, Main KM, Juul A \& Andersson AM 2014 Human urinary excretion of non-persistent environmental chemicals: an overview of Danish data collected 2006-2012. Reproduction 170 521-531. (doi:10.1530/REP-13-0522.R1)

Habert R, Muczynski V, Tiphany G, Moison D, Messiaen S, Frydman R, Benachi A, Delbes G, Lambrot R, Lehraiki A et al. 2014 Concerns with the widespread use of rodent models for human risk assess of Endocrine Disrupters. Reproduction 170 R119-R129. (doi:10.1530/REP-13-0497.R1)

Modick H, Weiss T, Dierkes G, Brüning T \& Koch H 2014 Ubiquitous presence of paracetamol in human urine: sources and implications. Reproduction 170 R105-R117. (doi:10.1530/REP-13-0527.R1) 